\title{
Epidermolysis bullosa simplex with mottled pigmentation
}

INSERM

\section{Source}

INSERM. (1999). Orphanet: an online rare disease and orphan drug data base.

Epidermolysis bullosa simplex with mottled pigmentation. ORPHA:79397

Epidermolysis bullosa simplex with mottled pigmentation (EBS-MP) is a basal subtype of epidermolysis bullosa simplex (EBS, see this term) characterized by generalized blistering with mottled or reticulate brown pigmentation. 